Nuñez, T. R., Radtke, T., \& Eimler, S. C. (2020). A third-person perspective on phubbing: Observing smartphoneinduced social exclusion generates negative affect, stress, and derogatory attitudes. Cyberpsychology: Journal of Psychosocial Research on Cyberspace, 14(3), Article 3. https://doi.org/10.5817/CP2020-3-3

\title{
A Third-Person Perspective on Phubbing: Observing Smartphone- Induced Social Exclusion Generates Negative Affect, Stress, and Derogatory Attitudes
}

\author{
Tania Roxana Nuñez ${ }^{1,2}$, Theda Radtke ${ }^{2}$, Sabrina Cornelia Eimler ${ }^{3}$ \\ ${ }^{1}$ Institute of Psychology, University of Wuppertal, Wuppertal, Germany \\ ${ }^{2}$ School of Psychology and Psychotherapy, Witten/Herdecke University, Witten, Germany \\ ${ }^{3}$ Institute of Positive Computing, University of Applied Sciences Ruhr West, Bottrop, Germany
}

\begin{abstract}
Phubbing (phone-snubbing) has become a pervasive public communication phenomenon which adversely affects its targets and sources. Yet, research on phubbing is not built on a consistent theoretical basis and examinations on its effects on the public are still missing. This study aimed at addressing these research gaps by conceptualizing the behavior as an act of smartphone-induced social exclusion and investigating whether phubbing impacts its observers. In a between-subject experiment, $N=160$ participants observed photos of dyadic interpersonal interactions in different everyday contexts which depicted one-sided, reciprocal, or no phubbing. Results revealed that observers of phubbing experienced negative affect and stress. Observers also derogated individuals who used their smartphones in social interactions regarding their warmth and competence; these effects were mediated by observers' perceived relationship quality between the observed persons. Affective and cognitive outcomes emerged independently of observers' gender. As these findings are in line with the effects and processes outlined in the temporal need-threat model of ostracism (i.e., social exclusion), they support the assumptions that phubbing is a form of smartphone-induced social exclusion and that its negative effects go beyond social interactions in which the behavior occurs. With this, the present study expands research regarding a modern communication phenomenon by strengthening its theoretical foundation and arriving at important theoretical and practical implications concerning targets, sources, and observers of phubbing.
\end{abstract}

Keywords: Phubbing; social exclusion; social interaction; observer perspective; smartphone use; mobile technology; human-computer interaction; experimental research

\section{Introduction}

Today, people frequently use their smartphones during face-to-face interactions (Vanden Abeele et al., 2019). This pervasive modern communication phenomenon, which has emerged as a byproduct of the omnipresence of smartphones and people's growing need to stay constantly connected (Elhai et al., 2017; Karadağ et al., 2015), is called phubbing (phone-snubbing; Roberts \& David, 2016). Studies have shown that phubbing is perceived as an irritating and impolite behavior (Aagaard, 2020) and that it can cause severe affective, cognitive, and behavioral impairments in interaction partners (see Al-Saggaf \& O'Donnell, 2019; Umari et al., 2019, for reviews). While such negative consequences have been identified for targets (i.e., those exposed to their interaction partners' disruptive smartphone use; e.g., Chotpitayasunondh \& Douglas, 2018; Vanden Abeele et al., 2016) and sources (i.e., those engaging in smartphone use while in an interaction with others; Ergün et al., 2019; Kushlev et al., 2019; Kushlev \& Heintzelman, 2018), no research to our knowledge has yet investigated third persons (i.e., observers of interactions 
in which the phenomenon occurs). The present study addresses this research gap by investigating adverse affective effects of phubbing on observers, observers' coping strategies, and relevant mediating and moderating influences. Herewith, the present study contributes to existing research in a twofold manner:

First, we aimed at deepening the understanding regarding the nature and scope of negative effects arising from phubbing as a real-life phenomenon which is commonly displayed in public and, therefore, directly or indirectly experienced by people on an everyday basis. This public pattern of occurrence and experience accentuates the need of expanding phubbing research to a third-person perspective.

Second, we sought to expedite the validation of a consistent theoretical foundation from which the effects of phubbing can be examined, evaluated, and predicted comprehensively. As existing research has drawn from various theoretical models and hypotheses to explain the detrimental effects of disruptive smartphone use during face-to-face interactions, scholars have begun to articulate a growing need for an overreaching theoretical basis (Vanden Abeele, 2020). In line with this, it has been suggested that the harmful nature of phubbing is a manifestation of threats posed upon humans' fundamental need to belong (Baumeister \& Leary, 1995; Sbarra et al., 2019) because phubbing is a smartphone-induced form of social exclusion (Chotpitayasunondh \& Douglas, 2018; Gonzales \& Wu, 2016; Hales et al., 2018). The examination of the third-person perspective should provide a deeper understanding of whether this theory holds true, because it has been shown that-as humans are extremely sensitive to inclusion norm violations-individuals are negatively influenced even by indirectly experienced social exclusion (Giesen \& Echterhoff, 2018; Wesselmann et al., 2009). Consequently, we aimed at expanding current research on the adverse effects of phone-snubbing to a third-person perspective and further validating a theoretical foundation facilitating the consistent study of this modern communication phenomenon.

\section{Phubbing: An Act of Social Exclusion}

Phubbing describes socially interfering smartphone use during face-to-face interactions. It manifests itself in dismissive behaviors such as sudden and often unexcused disruptions of ongoing conversations accompanied by averted gaze and body posture. Such verbal and nonverbal characteristics create moments of interpersonal disregard and may be perceived by interaction partners as phases of periodic silent treatment-something comparable to ostracism, the act of socially excluding or ignoring others (Chotpitayasunondh \& Douglas, 2018; Vanden Abeele, 2020; Williams, 2007, 2009). Consequently, scholars have suggested that phubbing is a smartphone-induced form of social exclusion (Chotpitayasunondh \& Douglas, 2018; Gonzales \& Wu, 2016; Hales et al., 2018; Vanden Abeele, 2020); a notion which appears to be consistent with recent studies demonstrating that targets of phubbing feel excluded by their interlocutors (David \& Roberts, 2017; Hales et al., 2018).

The adverse effects of (smartphone use-unrelated) ostracism have been studied extensively and have been outlined in the well-established main explanatory model of social exclusion, the temporal need-threat model of ostracism (Williams, 2007, 2009). Williams' model assumes in three temporally consecutive stages that experiencing social exclusion results in immediate affective impairments and threats to fundamental human needs (reflexive stage), delayed coping strategies (reflective stage), and long-term consequence on individual health (resignation stage). The present study aimed at examining reflexive and reflective effects of phubbing regarding third persons.

The reflexive stage of social exclusion is characterized by immediate negative mood, stress, or anger and threats to the human needs for belonging, self-esteem, control, and meaningful existence. According to the model, affective consequences are universal as they are adaptive processes operating to inform the individual about potential inclusion threats. In other words, social exclusion leads to immediate negative mood despite interindividual differences (e.g., gender; Blackhart et al., 2007) or contextual variations (e.g., underlying motives of ostracism; Zadro et al., 2004). In the reflective stage, targets apply different coping strategies to overcome the negative outcomes of experienced social exclusion (Williams, 2007, 2009). For instance, targets may become more prone to form friendships (Maner et al., 2007) and conform with others to regain inclusion in their social environment (Williams et al., 2000). Targets may also display aggressive or derogatory behaviors to reestablish feelings of control over the situation (Bourgeois \& Leary, 2001; Buckley et al., 2004). For example, socially excluded individuals have been shown to derogate their counterparts by evaluating them less favorably in terms of pleasantness, likability, and competence. According to the temporal need-threat model and ostracism research, 
such reflective coping strategies are moderated by various variables (e.g., gender, rejection sensitivity; Downey et al., 2004; Murray et al., 2002; Williams, 2007, 2009).

To this date, only three studies (Chotpitayasunondh \& Douglas, 2018; Gonzales \& Wu, 2016; Hales et al., 2018) have applied the temporal need-threat model of ostracism to phubbing (i.e., smartphone-induced social exclusion). Findings show that the phenomenon-just like smartphone use-unrelated ostracism-results in immediate negative mood (Chotpitayasunondh \& Douglas, 2018) and dissatisfaction of the four relevant fundamental human needs (Chotpitayasunondh \& Douglas, 2018; Gonzales \& Wu, 2016; Hales et al., 2018). Additionally, Chotpitayasunondh and Douglas (2018) found that neither rejection sensitivity nor perceived normativity of smartphone use moderated reflexive affective outcomes, thus, confirming the proposed universality assumption concerning the reflexive stage. In contrast, reflective effects of phubbing have not yet been studied based on the temporal need-threat model. However, findings deriving from other phubbing research appear to correspond with processes assumed in this stage. For instance, experiencing phubbing appears to result in enhanced online engagement, which could be an attempt of regaining social inclusion. David and Roberts (2017) revealed that the experience of phubbing led to higher social media use and Chotpitayasunondh and Douglas (2016) identified proneness to reciprocal phubbing following the exposure to intense smartphone use displayed by interaction partners. Studies have also found derogatory behaviors concerning phubbing interlocutors which may represent a coping strategy directed at regaining control. Przybylski and Weinstein (2013) demonstrated that smartphone presence in social interactions negatively influenced how trustworthy interaction partners evaluated one another. Vanden Abeele et al. (2016) found that participants rated their counterparts less attentive and less polite when those individuals used their smartphones during interactions than when they did not.

Consequently, recent research directly applying the temporal need-threat model to phubbing supports the occurrence of reflexive effects while other phubbing research also points towards a good fit of the model. Yet, more work is needed to replicate findings concerning reflexive effects of phubbing and expand the test of the model to reflective and ultimately resignation effects.

\section{Observing Social Exclusion Hurts}

Social exclusion does not exclusively affect individuals directly involved in an interaction. Neuroimaging studies illustrate that the dorsal anterior cingulate cortex, a brain area linked to the experience of physiological pain, is activated both when being socially excluded and when merely observing social exclusion of another person (Masten et al., 2011; Masten, Eisenberger, Pfeifer, Colich et al., 2013; Masten, Eisenberger, Pfeifer, \& Dapretto, 2013). Such findings support other research revealing physiological stress reactions such as heightened heart rate and increased electrodermal activity following the observation of social exclusion of others (Coyne et al., 2011). Negative affective reactions to observed events of social exclusion furthermore appear to reach a similar magnitude as those reported by immediate targets of ostracism (Giesen \& Echterhoff, 2018). Giesen and Echterhoff (2018) also demonstrated that, in addition to negative affect, viewed social exclusion produced needthreat to belonging, self-esteem, control, and meaningful existence in observers. The emergence of these reflexive effects in third persons demonstrates that humans are highly sensitive to social inclusion norm violations in their environment (Wesselmann et al., 2009).

Furthermore, observations of social exclusion may lead to reflective coping strategies in observers. Here, findings are diverse. Observers have been found to derogate sources of ostracism as an answer to their violation of social inclusion norms (Bourgeois \& Leary, 2001; Buckley et al., 2004; Masten et al., 2011). Additionally, they have shown to display comforting behaviors toward targets as a manifestation of empathy and interpersonal concern. Yet, observers may also devalue excluded individuals due to potentially biased perceptions concerning the targets' own responsibility for being disregarded (Park \& Park, 2015).

As stated earlier, research concerning the effects of phubbing on observers is still lacking. However, if phubbing is, in fact, a smartphone-induced form of social exclusion, similar reflexive and reflective effects as those revealed in smartphone use-unrelated ostracism studies may be expected to occur in observers of phubbing likewise. 


\section{Smartphone Use, Phubbing, and Gender}

Findings from smartphone use-unrelated social exclusion research and studies examining gender differences in smartphone use show that (observed) phubbing may influence women and men in distinctive ways. Research has revealed that women tend to be more sensitive to social exclusion cues (Benenson et al., 2013) and apply reflective coping strategies more readily in the face of potential exclusion threats than men (Baumeister \& Sommer, 1997; Benenson et al., 2011). Some studies have even found gender differences in the reflexive stage despite the universality assumption stated in the temporal need-threat model (Blackhart et al., 2007; Stroud et al., 2002). As for smartphone use-related research, studies have indicated that women tend to use their smartphones more often (van Deursen et al., 2015) and are more prone to problematic smartphone use than men (Wolniewicz et al., 2018). Furthermore, women tend to occupy themselves with their mobile devices based on relational motives such as communication and relationship maintenance whereas men utilize their smartphones more for information retrieval and entertainment (Kimbrough et al., 2013; Muscanell \& Guadagno, 2012; Twenge \& Martin, 2020). The use of the smartphone's social affordances such as SMS and social media networks also appears to be a main contributor to excessive smartphone consumption and phubbing (Karadağ et al., 2015). In line with this, it is not surprising that women tend to engage in phubbing more often than men (Chotpitayasunondh \& Douglas, 2016).

Some studies have identified gender effects in the context of phubbing, such as that women react more strongly to smartphone-induced social exclusion than men in terms of their perceived need-threat and pain (Hales et al., 2018). However, gender differences concerning phubbing are not consistently found in the literature (Al-Saggaf \& MacCulloch, 2019; Parmaksiz, 2019); thus, such findings are to be expanded within more rigorous investigations.

\section{Aims of the Present Study}

This study aimed at contributing to phubbing research by expanding its investigation to a third-person perspective and further validating the temporal need-threat model of ostracism as a theoretical foundation of the phenomenon. In order to do so, we tested whether observers of phubbing display reflexive affective reactions (i.e., immediate negative affect and stress) and reflective coping strategies (i.e., the derogation of phubbers on the dimensions warmth and competence). We also investigated potential gender effects and the mediating influence of perceived relationship quality on the link between observed phubbing and observers' derogation of phubbers. Consequently, this study aimed at replicating findings from the other three existing studies (Chotpitayasunondh \& Douglas, 2018; Gonzales \& Wu, 2016; Hales et al., 2018) which have examined the reflexive effects of phubbing based on the temporal need-threat model and expand phubbing research onto the reflective stage as such effects have not been studied yet in direct relation to the ostracism model.

Building on the subjective and physiological evidence deriving from smartphone use-unrelated social exclusion studies which were presented before (e.g., Coyne et al., 2011; Masten et al., 2011; Masten, Eisenberger, Pfeifer, \& Dapretto, 2013; Wesselmann et al., 2009), we hypothesized that observers of phubbing would experience detriments to their affective constitution and experience heightened stress.

Hypothesis 1. Observing phubbing will lead to (a) less positive affect, (b) more negative affect, and (c) more stress in observers.

The temporal need-threat model of ostracism assumes that reflexive effects of social exclusion are universal (Gonsalkorale \& Williams, 2007; Leary et al., 1998; Williams, 2007; Zadro et al., 2004; Zadro et al., 2006). In line with this universality assumption, we assumed that observers' gender would not moderate the reflexive effects of phubbing.

Hypothesis 2. Observers' gender will not moderate the effects of observed phubbing on (a) positive affect, (b) negative affect, and (c) stress in observers.

A common coping strategy in the reflective stage of social exclusion is the derogation of others (Williams, 2007, 2009). Research has found that phubbed individuals evaluate sources of phubbing as impolite and inattentive (Vanden Abeele et al., 2016). Smartphone use-unrelated studies suggest that observers may show similar reactions to phubbers due to the observed inclusion norm violation (Bourgeois \& Leary, 2001; Buckley et al., 2004; 
Masten et al., 2011). Consequently, we aimed at exploring the effects of phubbing on observers' person evaluation on the dimensions warmth and competence for targets and sources assuming that observers will derogate phubbers.

Hypothesis 3. Observers will evaluate sources of phubbing as (a) less warm and (b) less competent than targets of phubbing.

Following the investigation of gender effects in the reflexive stage, we also included observers' gender in the examination of reflective outcomes of observed phubbing. In line with the temporal need-threat model and evidence regarding women's proneness of reacting more strongly to exclusion threats than men (Baumeister \& Sommer, 1997; Benenson et al., 2011; Benenson et al., 2013), we hypothesized that female observers would derogate phubbers more than male observers.

Hypothesis 4. The effect of observed phubbing on observers' evaluation concerning sources' (a) warmth and (b) competence will be more pronounced for female than for male observers.

Lastly, phubbing impairs individuals' perceived relationship quality because phubbers violate social inclusion norms (Chotpitayasunondh \& Douglas, 2018; McDaniel \& Coyne, 2016; Przybylski \& Weinstein, 2013; Roberts \& David, 2016). Consequently, we assumed that observers would not derogate phubbers simply because of their smartphone use but because of the dysfunctional relationship they are creating by attending to their smartphones.

Hypothesis 5. The negative effect of observed phubbing on observers' evaluation concerning its sources' (a) warmth and (b) competence will be mediated by decreases in observers' perceived relationship quality.

\section{Method}

\section{Experimental Design}

We investigated the hypothesized effects by implementing a between-subject design. During an online experiment, participants saw six photos of dyadic interpersonal interactions between a man and a woman in three of which phubbing was systematically varied. The manipulation resulted in four conditions (man phubs, woman phubs, reciprocal phubbing, no phubbing) to which participants were randomly assigned.

\section{Participants}

We recruited a total of 161 participants through on- and off-campus advertisements, online platforms (e.g., Facebook), and email correspondence. One participant had to be excluded from the analysis due to disregard of the experimental instructions. Consequently, the final sample consisted of $N=160$ participants (97 female, 61 male, 2 diverse) with a mean age of $28.8(S D=12.82)$ years ranging from 15 to 90 years $\left(g_{1}=1.88, S E=0.19 ; g_{2}=\right.$ $3.47, S E=0.38$ ). Skewness of the age distribution was still in the acceptable range (Pituch \& Stevens, 2015); therefore, we did not apply any transformation to the data. Most participants were university students (50.2\%); others indicated being employees (26.3\%), trainees (7.5\%), high school students (6.3\%) or did not further specify their occupational status. Subjects participated voluntarily; students received course credit for their contribution. All participants were naive to the different experimental conditions and the overall purpose of the study.

\section{Procedure}

We told participants that they would be taking part in an online experiment on attentional processes and informed them about the course of the experiment, the anonymity of their data as well as their right to withdraw from their participation at any time. Before the photo presentation, we instructed participants to look at the photos as attentively as possible before answering the subsequent questions. Importantly, we asked participants to merely observe the shown situations and not try to identify with the portrayed individuals. 
Participants saw the experimental and neutral photos (see Figure 1) in random order and were presented questions concerning the following variables after each photo presentation: observers' affect, observers' stress, and perceived relationship quality. Participants' person evaluations concerning the observed individuals' warmth and competence were assessed after all photos had been shown. Before gathering sociodemographic data, we also controlled for participants' acquaintance with the shown subjects and their perception of smartphone presence in the photos. Finally, we provided everyone with a debriefing on the study's objectives. All participants were treated in accordance to the Declaration of Helsinki.

\section{Experimental Stimuli}

Participants were presented six photos of dyadic interpersonal interactions of a young man and woman in different everyday situations (see Figure 1). Three photos showing the couple interacting at a dining table (A.1), cooking together in the kitchen (A.2), and interacting at a ticket machine (A.3) were used as experimental stimuli varying in exhibited phubbing behavior corresponding to the respective experimental condition. For instance, participants in the man phubs-condition always saw the man phub in the three experimental situations; participants in the reciprocal phubbing-condition always saw both individuals phub in the three contexts. Three additional photos (B) showing the subjects sitting together at a table, interacting in the hallway before leaving the house, and conversing outside while waiting for the bus were used as neutral material in order to reduce participants' suspicion concerning the study's objective. No phubbing was shown in these photos. These neutral stimuli were also presented in each condition. We chose to utilize different everyday contexts as we presumed that contextual factors might impact the observation of phubbing. In our analysis, we collapsed the data of the repeated measures acquired after each experimental context in order to cancel out possible differential effects posed by context and more exclusively investigate the impact of phubbing on observers. All experimental and neutral stimuli were created by student photographers. Photographers utilized natural lighting to prevent an artificial look of the material and always portrayed the same two individuals on each photo. For experimental stimuli, photographers ensured similar posture and facial expressions of the shown individuals in all phubbing variations of the same situation. 
A.1

A. 2

A.3

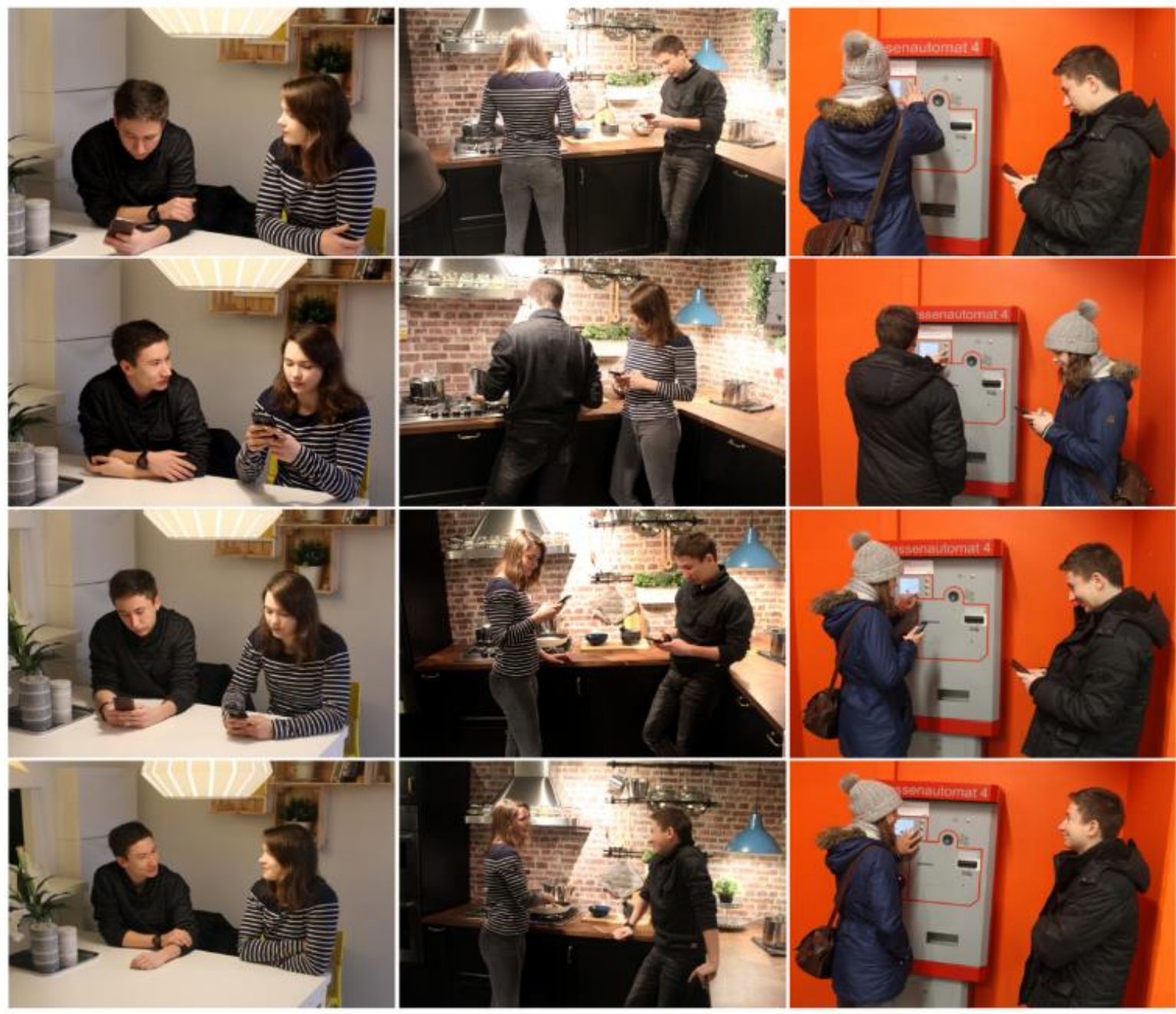

$\mathrm{B}$
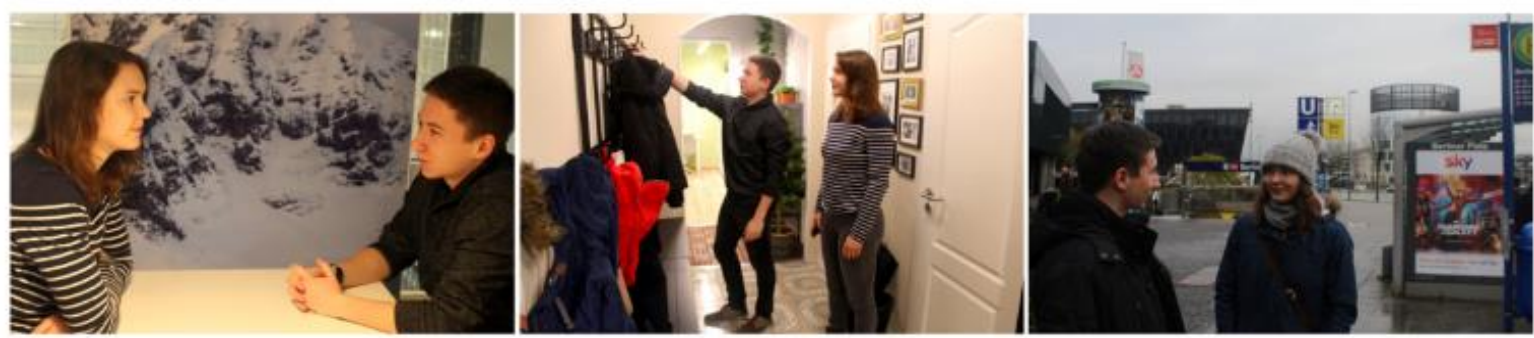

Note. Presented photos of dyadic interactions serving as experimental (A) and neutral stimuli (B). Experimental stimuli represented photos showing the individuals interacting at a table (A.1), in the kitchen (A.2), and at a ticket machine (A.3) and varied in phubbing behavior (man phubs, woman phubs, reciprocal phubbing, no phubbing).

\section{Measures}

\section{Observers' Affect}

We measured observers' affect using the Scale of Positive and Negative Experience (Diener et al., 2010). By applying this measure, we were able to investigate the effects of observed phubbing both on observers' positive and negative affect (see Appendix for an overview of all utilized items). Participants were to indicate their current feelings based on six positive (e.g., I feel "...good" or "...happy"; $a_{\text {table }}=.96$, $a_{\text {kitchen }}=.97$, $a_{\text {ticket machine }}=.95$ ) and six negative items (e.g., I feel "...bad" or "...sad"; $a_{\text {table }}=.91$, $a_{\text {kitchen }}=.93$, $a_{\text {ticket machine }}=.93$ ) on a 5-point Likert-type scale ranging from strongly disagree (1) to strongly agree (5). This scale was applied as a repeated measure after each photo presentation. 


\section{Observers'Stress}

Observers' stress resulting from the observed situation was measured with one item asking participants to indicate their current stress level ("Please indicate how stressed you feel concerning the observed situation."). Participants were to indicate their stress experience on a 5-point Likert-type scale ranging from not stressed at all (1) to very stressed (5). This measure also followed each photo presentation.

\section{Observers' Perceived Relationship Quality}

We measured perceived relationship quality with self-developed items based on the Partner and Relationship Ideal Scales (Fletcher et al., 1999). Fletcher et al. collected 17 characteristics of relationship ideals. From these characteristics, we selected those that best reflected interpersonal connectedness (i.e., "honest", "trusting", "friendship", "good communication", "understanding" and "in love"). Based on these items, we created 10 statements (e.g., The two people "...communicate well with each other" or "...know each other well"; $a_{\text {table }}=.94$, $a_{\text {kitchen }}=.96$, $\alpha_{\text {ticket machine }}=.96$ ) that participants were to answer after each photo presentation on a 5-point Likerttype scale ranging from strongly disagree (1) to strongly agree (5).

\section{Observers' Person Evaluation}

Observers' evaluations of the viewed individuals were assessed using items derived from the Stereotype Content Model (SCM, Cuddy et al., 2008). We used 11 items covering the dimensions warmth (e.g., The person is "...friendly" or "...sincere"; $a_{\operatorname{man}}=.91, a_{\text {woman }}=.93$ ) and competence (e.g., The person is "...intelligent" or "...skillful"; $a_{\operatorname{man}}=.86$, $\left.a_{\text {woman }}=.86\right)$ for both observed individuals. Responses were given on a 5-point Likert-type scale from strongly disagree (1) to strongly agree (5). As these measures covered interpersonal attributions which are considered quite stable, we only conducted them once after all photos had been presented.

\section{Statistical Analysis}

To test hypotheses 1 and 2, we conducted two-way univariate analyses of covariance (ANCOVA) for observers' positive affect, negative affect, and stress, including the factors phubbing (with its four levels: man phubs, woman phubs, reciprocal phubbing, no phubbing) and observers' gender as independent variables. In order to test hypotheses 3 and 4, we calculated two-way multivariate analyses of covariance (MANCOVA) for the combined dependent variables observed individuals' warmth and competence, integrating phubbing and observers' gender as independent variables. The variable observers' age was included as a covariate in all analyses. We chose to control for age as younger individuals have been shown to exhibit a different relationship to technology than older people (Andone et al., 2016; Kadylak et al., 2018). Consequently, there may be different norm perceptions around smartphone use in social interactions for adolescents or young adults compared to older individuals. An assumption check showed normality of the data across all group combinations of phubbing condition and gender as assessed by visual inspection of Normal Q-Q Plots. Homogeneity of variances regarding all dependent variables was confirmed by Levene's Test of variance, $p>.05$. Regarding the analyses for hypotheses 3 and 4 , homogeneity of covariance matrices was confirmed for the combined dependent variables man's warmth and competence by Box's Test, $p>.05$. For the combined dependent variables woman's warmth and competence, Box's Test was significant, $p=.044$. Yet, as it has been recommended to test Box 's Test based on significance values of $.025, .01$ (Mertler \& Reinhart, 2016), or .001 (Verma, 2015; Warner, 2012), we proceeded with the analyses. Furthermore, there was no evidence of multicollinearity as assessed by Pearson correlation $(|r|<0.9)$.

In order to test hypothesis 5, we used model 4 of the SPSS macro PROCESS V3.0 (Hayes, 2018) including phubbing (phubbing vs. no phubbing) as predictor variable, man's or woman's warmth and competence as outcome variables, and observers' perceived relationship quality as mediator. As in prior analyses, we controlled for observers' age. Our analyses were based on 5,000 bootstrapped samples and a $p$-value of .05. Visual inspection of Normal P-P Plots and histograms plotting standardized predicted values against standardized residuals supported normality of the data and showed no violations of the linearity and homoscedasticity assumptions. 


\section{Results}

\section{Manipulation and Randomization Check}

Most participants indicated having seen a smartphone in the phubbing-conditions (man phubs: 89\%; woman phubs: 97\%; reciprocal phubbing: $87 \%$ ) and not having seen a smartphone in the no phubbing-condition (76\%). This shows that smartphone presence was quite salient, but that the combination of experimental and neutral photos might have served the intended purpose of decreasing the prominence of presented phubbing behavior. In order to test the distribution of the moderating variable observers' gender, we performed a chi-square test confirming that the variable was independently distributed across conditions, $\chi^{2}(3)=5.90, p=.12$.

\section{Observers' Affect and Stress}

We hypothesized that (hypothesis 1) participants observing phubbing would experience (a) less positive affect (b) more negative affect and (c) more stress. We also assumed that (hypothesis 2 ) these negative reflexive affective effects would be unmoderated by observers' gender. Mean values for all four conditions concerning the dependent variables positive affect, negative affect and stress are presented in Table 1. For interpretational clarity, it should be noted that the following results contain $\eta_{p}{ }^{2}$-values; partial eta squared is an effect size that can be interpreted as follows: small: .01, medium: .06, large: .14 (Richardson, 2011).

Table 1. Mean Scores for Observers' Positive and Negative Affect and Stress Across Conditions.

\begin{tabular}{|c|c|c|c|c|c|c|}
\hline \multirow{2}{*}{ Condition } & \multicolumn{2}{|c|}{ Positive affect } & \multicolumn{2}{|c|}{ Negative affect } & \multicolumn{2}{|c|}{ Stress } \\
\hline & $M(S E)$ & $95 \% \mathrm{Cl}$ & $M(S E)$ & $95 \% \mathrm{Cl}$ & $M(S E)$ & $95 \% \mathrm{Cl}$ \\
\hline Man phubs & $14.76(.75)$ & {$[13.28,16.23]$} & $12.59(.76)$ & {$[11.09,14.10]$} & $2.27(.14)$ & {$[2.00,2.54]$} \\
\hline Woman phubs & $15.40(.78)$ & {$[13.86,16.95]$} & $12.91(.80)$ & {$[11.34,14.49]$} & $2.22(.14)$ & {$[1.93,2.50]$} \\
\hline Reciprocal phubbing & $13.85(.72)$ & {$[12.42,15.27]$} & $11.89(.74)$ & {$[10.43,13.35]$} & $1.93(.13)$ & {$[1.67,2.19]$} \\
\hline No phubbing & $20.74(.71)$ & {$[19.35,22.13]$} & $7.90(.72)$ & {$[6.47,9.32]$} & $1.35(.13)$ & {$[1.10,1.61]$} \\
\hline
\end{tabular}

Note. The analyses are controlled for observers' age.

\section{Positive Affect}

We found a significant main effect of phubbing on positive affect, $F(3,147)=18.94, p<.001, \eta_{\mathrm{p}}{ }^{2}=.28$, but not of observers' gender, $F(1,147)=1.16, p=.28$, nor an interaction between phubbing and gender, $F(3,147)=0.33, p=$ .80. Sidak corrected post-hoc comparisons indicated that participants who did not observe phubbing in the interaction between the man and woman reported more positive affect than those who saw the man phub ( $p<$ $.001)$, the woman phub $(p<.001)$, and both individuals phub $(p<.001)$. Consequently, differences emerged between the no phubbing-condition and all phubbing-conditions but not between the different phubbingconditions.

\section{Negative Affect}

Our analysis identified a significant main effect of phubbing on negative affect, $F(3,147)=9.98, p<.001, \eta_{p}^{2}=.17$, but not of observers' gender, $F(1,147)=1.75, p=.19$, nor an interaction effect between the two factors, $F(3,147)=$ $0.25, p=.86$. Sidak adjusted post-hoc analyses revealed that participants experienced less negative affect in the no phubbing-condition than in the man phubs- $(p<.001)$, woman phubs- $(p<.001)$, and reciprocal phubbingcondition $(p<.001)$.

\section{Stress}

We found a significant main effect of phubbing on stress, $F(3,147)=10.12, p<.001, \eta_{p}^{2}=.17$, and of observers' gender, $F(1,147)=4.57, p=.034, \eta_{\mathrm{p}}^{2}=.030$, but no interaction between phubbing and gender, $F(3,147)=1.02, p=$ .39. Sidak corrected post-hoc comparisons indicated that participants in the no phubbing-condition felt less stressed than those in the man phubs- $(p<.001)$, woman phubs- $(p<.001)$, and reciprocal phubbing-condition $(p$ 
$=.006)$. As for gender differences, post-hoc comparisons showed that, overall, women $(M=2.09, S E=.084)$ were more stressed than men $(M=1.80, S E=.11 ; p=.034)$.

\section{Observers' Person Evaluation}

We hypothesized that (hypothesis 3) participants observing phubbing in the interaction between the shown man and woman would derogate the individual who phubbed in terms of his or her (a) warmth and (b) competence. We also assumed that (hypothesis 4) these reflective effects of phubbing on person evaluation would be moderated by observers' gender in that female observers derogate phubbers more than male observers. Mean scores of observers' warmth and competence evaluations for the man and the woman across all four conditions are presented in Table 2 .

As for observers' evaluation of the man, the MANCOVA indicated a main effect for phubbing, $V=.26, F(6,294)=$ $7.21, p<.001, \eta_{p}^{2}=.13$, but neither a main effect of observers' gender, $V=.002, F(2,146)=.17, p=.85$, nor an interaction between the independent variables, $V=.030, F(6,294)=.74, p=.62$. Univariate analyses indicated that both the man's warmth, $F(3,147)=6.49, p<.001, \eta_{p}^{2}=.12$, and competence, $F(3,147)=15.32, p<.001, \eta_{p}^{2}=.24$, were significantly affected by phubbing. Observers' evaluation concerning the man's warmth was also significantly affected by the covariate age, $F(1,147)=5.37, p=.022, \eta_{p}^{2}=.035$.

As for observers' ratings concerning the woman, MANCOVA results revealed a main effect of phubbing, $V=.19$, $F(6,294)=5.08, p<.001, \eta_{p}^{2}=.094$, but neither a main effect for observers' gender, $V=.010, F(2,146)=.74, p=.48$, nor an interaction between phubbing and gender, $V=.031, F(6,294)=.76, p=.60$, on the combined dependent variables. Univariate tests showed significant results for phubbing on both the woman's warmth, $F(3,147)=9.51$, $p<.001, \eta_{\mathrm{p}}^{2}=.16$, and competence, $F(3,147)=4.96, p=.003, \eta_{\mathrm{p}}^{2}=.092$.

\section{Evaluations of Phubbers' Warmth}

Our analyses showed that the man and woman were perceived less warm by observers when they phubbed onesidedly compared to when no phubbing occurred in the interaction (man: $p=.020$; woman: $p<.001$ ). While observers did not evaluate the man worse when he phubbed the woman than when he was phubbed by the female interaction partner $(p=.054)$, the woman was rated less warm when she phubbed the male counterpart compared to when she was the target of one-sided phubbing $(p<.001)$. Both the man and the woman were also perceived less warm when they reciprocally phubbed over when they were targets of one-sided phubbing (man: $p=.007$; woman: $p<.011$ ) and when no phubbing occurred in the interaction (man: $p=.001$; woman: $p=.001$ ).

\section{Evaluations of Phubbers' Competence}

Table 2. Mean Scores for Observers' Evaluation of the Observed Man's and Woman's Warmth and Competence Across Conditions.

\begin{tabular}{|c|c|c|c|c|c|c|c|c|}
\hline \multirow[t]{2}{*}{ Condition } & \multicolumn{2}{|c|}{ Man's warmth } & \multicolumn{2}{|c|}{ Man's competence } & \multicolumn{2}{|c|}{ Woman's warmth } & \multicolumn{2}{|c|}{$\begin{array}{c}\text { Woman's } \\
\text { competence }\end{array}$} \\
\hline & $M(S E)$ & $95 \% \mathrm{Cl}$ & $M(S E)$ & $95 \% \mathrm{Cl}$ & $M(S E)$ & $95 \% \mathrm{Cl}$ & $M(S E)$ & $95 \% \mathrm{Cl}$ \\
\hline Man phubs & $\begin{array}{l}3.02 \\
(.11)\end{array}$ & $\begin{array}{l}2.80, \\
3.24]\end{array}$ & $\begin{array}{l}2.83 \\
(.12)\end{array}$ & $\begin{array}{l}{[2.59,} \\
3.07]\end{array}$ & $\begin{array}{l}3.70 \\
(.14)\end{array}$ & $\begin{array}{l}3.44, \\
3.97]\end{array}$ & $\begin{array}{l}3.45 \\
(.12)\end{array}$ & $\begin{array}{l}{[3.23,} \\
3.68]\end{array}$ \\
\hline Woman phubs & $\begin{array}{l}3.41 \\
(.12)\end{array}$ & $\begin{array}{l}{[3.18,} \\
3.65]\end{array}$ & $\begin{array}{l}3.72 \\
(.13)\end{array}$ & $\begin{array}{l}{[3.46,} \\
3.97]\end{array}$ & $\begin{array}{l}2.90 \\
(.14)\end{array}$ & $\begin{array}{l}{[2.62,} \\
3.18]\end{array}$ & $\begin{array}{l}3.02 \\
(.12)\end{array}$ & $\begin{array}{l}{[2.78,} \\
3.26]\end{array}$ \\
\hline Reciprocal phubbing & $\begin{array}{l}2.91 \\
(.11)\end{array}$ & $\begin{array}{l}{[2.70,} \\
3.13]\end{array}$ & $\begin{array}{l}2.94 \\
(.12)\end{array}$ & $\begin{array}{l}{[2.71,} \\
3.17]\end{array}$ & $\begin{array}{l}3.15 \\
(.13)\end{array}$ & $\begin{array}{l}{[2.89} \\
3.41]\end{array}$ & $\begin{array}{l}2.98 \\
(.11)\end{array}$ & $\begin{array}{l}{[2.76,} \\
3.20]\end{array}$ \\
\hline No phubbing & $\begin{array}{l}3.49 \\
(.11)\end{array}$ & $\begin{array}{l}{[3.27,} \\
3.70]\end{array}$ & $\begin{array}{l}3.70 \\
(.12)\end{array}$ & $\begin{array}{l}{[3.47,} \\
3.93]\end{array}$ & $\begin{array}{l}3.75 \\
(.13)\end{array}$ & $\begin{array}{l}{[3.49} \\
4.00]\end{array}$ & $\begin{array}{l}3.41 \\
(.11)\end{array}$ & $\begin{array}{l}{[3.20,} \\
3.63]\end{array}$ \\
\hline
\end{tabular}

Note. The analyses are controlled for observers' age.

Our analyses showed that for both the man and the woman, observers evaluated the individuals less competent when they phubbed over when they were targets of phubbing (man: $p<.001$; woman: $p=.030$ ) and when no phubbing was displayed in the interaction (man: $p<.001$; woman: $p=.047$ ). Moreover, both the man and the 
woman were rated less competent when reciprocal phubbing occurred than when they were targets of one-sided phubbing (man: $p<.001$; woman: $p=.020$ ) and when no phubbing occurred (man: $p<.001$; woman: $p=.033$ ).

\section{Mediation of Perceived Relationship Quality}

We hypothesized that (hypothesis 5) the negative effects of phubbing on observers' person evaluations concerning the man's and woman's warmth and competence would be mediated by decreases in observers' perceived relationship quality between the individuals. As prior analyses on person evaluation concerning the man and the woman did not indicate significant differences between the phubbing-conditions (being the source of phubbing vs. reciprocal phubbing) and between the conditions in which the respective individual did not display phubbing behaviors (being the target of phubbing vs. no phubbing), those conditions were collapsed for the respective individuals. Consequently, for the analyses concerning observers' evaluation of the man's warmth and competence, the man phubs- and reciprocal phubbing-conditions were collapsed to a phubbing-condition and the woman phubs- and no phubbing-conditions were grouped to a no phubbing-condition. For evaluations concerning the woman, the woman phubs- and reciprocal phubbing-conditions were collapsed, and the man phubs- and no phubbing-conditions were combined.

Figure 2. Mediation Model.
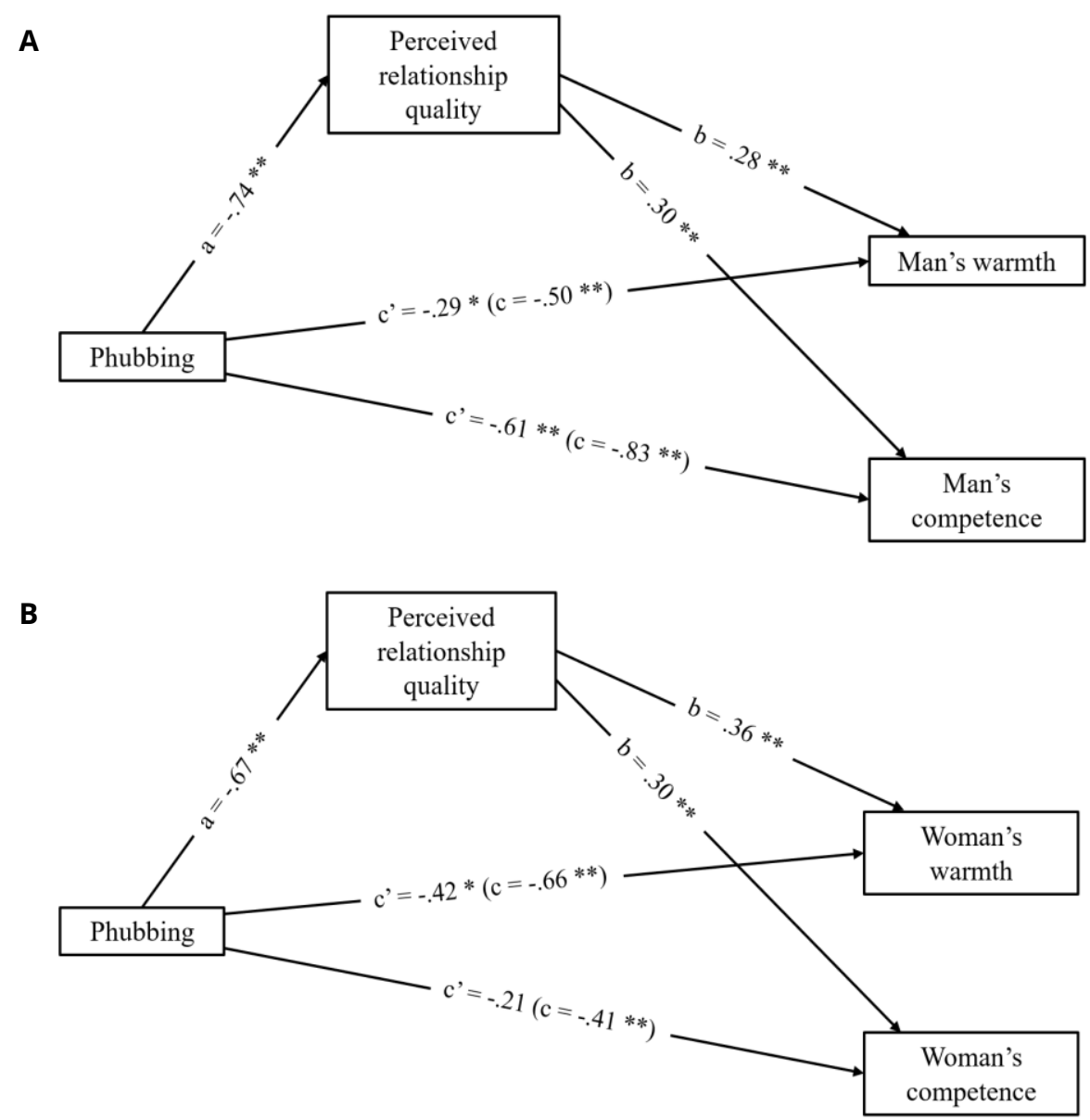

Note. Indirect effects of phubbing on observers' evaluation of $(A)$ the observed man's warmth and competence and (B) the observed woman's warmth and competence through observers' perceived relationship quality between the man and the woman (unstandardized regression coefficients, with total effects in parentheses). ${ }^{*} p<.05 ;{ }^{* \star} p<.001$.

As can be seen in Figure 2 and Table 3, our analyses revealed mediating influences of observers' perceived relationship quality on the effects of phubbing on person evaluation concerning the warmth and competence of the man and woman. For the observed man, results indicated that the effects of phubbing on observers' person evaluation decreased both for man's warmth and competence after perceived relationship quality was included as a mediator. Yet, these direct effects remained significant indicating only a partial mediation. The mediation model including perceived relationship quality as mediator and controlling for observers' age explained $23 \%$ of 
the variance concerning the man's warmth, the model concerning his competence accounted for $32 \%$ of the variance in the dependent variable. Similarly, for the observed woman, the mediation analysis showed a reduction in the effects of phubbing on observers' evaluation concerning her warmth and competence when the mediator was included. While the direct effect concerning the woman's warmth remained significant indicating a partial mediation, the direct effect concerning her competence became insignificant after incorporating perceived relationship quality as a mediator indicating a full mediation. The mediation model including perceived relationship quality as mediator and controlling for observers' age accounted for $24 \%$ of the variance concerning the woman's warmth, the model concerning her competence explained $19 \%$ of the variance in the dependent variable. Table 3 indicates both the unstandardized and partially standardized indirect effects for the calculated mediation models. The partially standardized indirect effect reflects the number of standard deviations by which the dependent variables (man's/woman's warmth/competence) will increase or decrease indirectly through the mediating variable (perceived relationship quality) with each change in the independent variable (phubbing) (Preacher \& Kelley, 2011).

Table 3. Mediation Model (PROCESS, Model 4): Indirect Effects of Phubbing (IV) on Observers' Person Evaluation of the Observed Man and Woman (DV) Through Observers' Perceived Relationship Quality (Mediator).

\begin{tabular}{|c|c|c|c|c|c|c|}
\hline & \multicolumn{3}{|c|}{ Observed man } & \multicolumn{3}{|c|}{ Observed woman } \\
\hline & $B$ & $S E$ & $p$ & $B$ & $S E$ & $p$ \\
\hline \multicolumn{7}{|l|}{ Mediator model (DV = Relationship quality) } \\
\hline Predictor & & & & & $\ll<<$ & \\
\hline Phubbing ${ }^{a}$ & -.74 & .11 & $<.001$ & -.67 & .12 & $<.001$ \\
\hline \multicolumn{7}{|l|}{ DV model (DV = Individual's warmth) } \\
\hline \multicolumn{7}{|l|}{ Predictors } \\
\hline Relationship quality & .28 & .073 & $<.001$ & .36 & .083 & $<.001$ \\
\hline Phubbing (direct effect) & -.29 & .12 & .014 & -.42 & .13 & .001 \\
\hline \multicolumn{7}{|l|}{ DV model (DV = Individual's competence) } \\
\hline \multicolumn{7}{|l|}{ Predictors } \\
\hline Relationship quality & .30 & .079 & $<.001$ & .30 & .070 & $<.001$ \\
\hline Phubbing (direct effect) & -.61 & .13 & $<.001$ & -.21 & .11 & .062 \\
\hline \multicolumn{7}{|l|}{ Total effect } \\
\hline Phubbing $\rightarrow$ Individual's warmth & -.50 & .11 & $<.001$ & -.66 & .13 & $<.001$ \\
\hline Phubbing $\rightarrow$ Individual's competence & -.83 & .12 & $<.001$ & -.41 & .11 & $<.001$ \\
\hline Indirect effects & $B$ & Boot SE & Boot 95\% Cl & $B$ & Boot SE & Boot $95 \% \mathrm{Cl}$ \\
\hline $\begin{array}{l}\text { Phubbing } \rightarrow \text { Relationship quality } \rightarrow \text { Individual's } \\
\text { warmth }\end{array}$ & -.21 & .068 & {$[-.35,-.087]$} & -.24 & .078 & {$[-.41,-.10]$} \\
\hline $\begin{array}{l}\text { Phubbing } \rightarrow \text { Relationship quality } \rightarrow \text { Individual's } \\
\text { competence }\end{array}$ & -.22 & .084 & {$[-.41,-.077]$} & -.20 & .070 & {$[-.35,-.081]$} \\
\hline Partially standardized indirect effect & $\beta$ & Boot SE & Boot 95\% Cl & $\beta$ & Boot SE & Boot $95 \% \mathrm{Cl}$ \\
\hline $\begin{array}{l}\text { Phubbing } \rightarrow \text { Relationship quality } \rightarrow \text { Individual's } \\
\text { warmth }\end{array}$ & -.28 & .087 & {$[-.47,-.13]$} & -.28 & .083 & {$[-.46,-.13]$} \\
\hline $\begin{array}{l}\text { Phubbing } \rightarrow \text { Relationship quality } \rightarrow \text { Individual's } \\
\text { competence }\end{array}$ & -.26 & .095 & {$[-.47,-.094]$} & -.29 & .088 & {$[-.47,-.13]$} \\
\hline
\end{tabular}

\section{Discussion}

The present study examined whether phubbing adversely impacts its observers' affective constitution and person evaluation. To our knowledge, this is the first empirical investigation into the effects of phubbing that goes beyond direct interaction partners. By conceptualizing phubbing as a smartphone-induced form of social exclusion, we also aimed at strengthening a theoretical basis regarding this modern communication phenomenon. 


\section{Theoretical and Empirical Implications}

As expected, our results indicated that observers of phubbing underwent decreases of positive and increases of negative affect as well as elevated stress levels (hypothesis 1) which emerged independently of observers' gender (hypothesis 2). Theoretically, this is in line with the reflexive stage of the temporal need-threat model of ostracism, which assumes that adverse affective consequences occur immediately and universally (Williams, 2007, 2009). The results are also consistent with research demonstrating that smartphone use-unrelated social exclusion impacts the affective well-being of observers in similar ways as those of direct targets (Giesen \& Echterhoff, 2018; Masten, Eisenberger, Pfeifer, \& Dapretto, 2013; Wesselmann et al., 2009)

It is important to stress that affective detriments occur because social exclusion threatens the fundamental human need for meaningful interpersonal closeness (Baumeister \& Leary, 1995; Wesselmann et al., 2009). As interpersonal closeness is inherently connected to humans' well-being, people possess a very sensitive system to detect potential inclusion threats in their social environment leading to empathetic responses even in observers of such threats (Wesselmann et al., 2009). Consequently, the evidence showing that third persons experience negative affect and stress even though observed phubbing is not directed at them and not displayed by their important others, suggests that phone-snubbing could be a serious inclusion norm violation with severe outcomes for human well-being.

We also found that observers were similarly affected by one-sided and reciprocal phubbing. Consequently, for observers, phubbing may not only be problematic because individuals exclude their immediate interlocutors but because people exclude others and themselves from valuable social interactions through technology use. While this, again, illustrates humans' strong need for immediate social connections, it also warrants the concern about ever-increasing smartphone use in social contexts and the growing need to be constantly online. Existing research has demonstrated that one-sided phubbing can impair targets' (Chotpitayasunondh \& Douglas, 2018; Gonzales \& Wu, 2016; Hales et al., 2018) and sources' well-being (Kushlev et al., 2019; Kushlev \& Heintzelman, 2018; Sbarra et al., 2019); yet, to our knowledge, studies on mutual phubbing are still missing. Consequently, future research should examine the effects of reciprocal phubbing on direct interaction partners in order to ascertain whether respective effects align with those found in this study.

Our result also showed no moderating influences of observers' gender on the adverse affective outcomes of phubbing. While this is in line with the temporal need-threat model (Williams, 2007, 2009), it is not consistent with some recent research showing that female targets of phubbing experience greater subjective pain than male targets (Hales et al., 2018). It is likely that these inconsistencies are due to measurement-specific issues of reflexive effects in general which will be discussed in detail later.

Consistent with our assumptions, observers also derogated sources of phubbing by evaluating them as less warm and less competent (hypothesis 3). These effects are in line with the reflective stage of the temporal need-threat model assuming that targets will display behavioral and cognitive coping strategies (e.g., the derogation of others) to reduce negative outcomes arising from the exclusion event (Bourgeois \& Leary, 2001; Buckley et al., 2004; Williams, 2007, 2009). Our results are also consistent with research concluding that targets of phubbing evaluate phubbers as impolite and inattentive (Vanden Abeele et al., 2016).

Unexpectedly and in contrast to the temporal need-threat model (Williams, 2007, 2009), the present study found no moderation of observers' gender on the effect of observed phubbing on person evaluation. Considering women's proneness to detecting exclusion cues (Benenson et al., 2013) and the heightened importance they ascribe to interpersonal closeness compared to men (Baumeister \& Sommer, 1997), gender differences would have been expected to emerge in the reflective stage of observed phubbing. While the lack of moderation might be due to the small number of male participants in this study, it may also be that gender differences simply do not play such an important role concerning the third-person perspective which, however, needs to be further examined in future research.

Finally, in support of our hypothesis, the effects of observed phubbing on the derogation of phubbers were-at least partially - mediated by observers' perceived relationship quality between the viewed individuals (hypothesis 5). This finding shows that observers' empathy and their comprehension of the disruptive effect of phubbing on 
interpersonal interactions are important processes underlying reflective reactions to smartphone-induced social exclusion. While these findings are in line with prior research showing that negative affective outcomes of phubbing are mediated by factors such as interpersonal conflict and decreases in relationship satisfaction (David \& Roberts, 2017; Roberts \& David, 2016; Wang et al., 2017), they also support our prior claim that negative effects of phubbing are due to the disruption of beneficial social processes.

This study adds more evidence to the assumption that phubbing is an act of smartphone-induced social exclusion, which, together with other recent scientific work (Chotpitayasunondh \& Douglas, 2018; Gonzales \& Wu, 2016; Hales et al., 2018), should motivate future research to base their investigations on this link. In fact, even less theoretical phubbing studies are in some way or another build on the idea that smartphone use in immediate interactions thwarts important social benefits. While these studies have assumed, for instance, that the negative impact of phubbing originates in the time lost with important others as stated in the displacement hypothesis (Roberts \& David, 2016; Turkle, 2011; Wang et al., 2017), reduced exclusive interpersonal attention and jealousy (Krasnova et al., 2016), or a lack of nonverbal immediacy cues (Nazir \& Pişkin, 2016), it all appears to boil down to the impairment of humans' fundamental need to belong (Baumeister \& Leary, 1995). More precisely, while factors such as attentional deficits, jealousy, or nonverbal behaviors are important aspects to consider in phubbing research, they can only explain negative outcomes in certain circumstances or for certain interaction partners. Yet, building on the theoretical basis of social exclusion and utilizing the well-established temporal need-threat model of ostracism - which appears to be a good fit-may allow for a more comprehensive and consistent examination of phubbing for various reasons:

First, it has been demonstrated that the reflexive and reflective effects proposed in the model can be found in direct targets of phubbing (Chotpitayasunondh \& Douglas, 2018; Gonzales \& Wu, 2016; Hales et al., 2018) and, according to the present study, in observers. The model should also be applicable to sources of phubbing as they exclude themselves from social interactions (Sbarra et al., 2019). Second, the model can be used for phubbing investigations in a variety of contexts (e.g., the family context, partner phubbing, phubbing at the workplace). Third, the model outlines short- and long-term effects, both of which are highly important in the investigation of phubbing. There are various opportunities for future research on phubbing based on the temporal need-threat model. For instance, future research may measure the reflexive affective effects of phone-snubbing not only with subjective self-report instruments but also through physiological stress parameters as such immediate affective impairments are fleeting in nature. Furthermore, more research on the reflective effects of phubbing is needed. Here, it would be interesting to examine under which circumstances people who are directly or indirectly affected by phubbing apply coping strategies aimed at regaining inclusion or control. If phubbing leads to inclusion-seeking, it would also be of value to explore whether people (targets, sources, and observers alike) tend to do so off- or online. In this context, potential influencing factors such as smartphone dependency and other technology addictions as well as individual vulnerabilities such as social anxiety should be considered as these have been found to be associated with phubbing behaviors (Guazzini et al., 2019). As phubbing is such a pervasive public phenomenon, we also need to address the long-term consequences-in other words, the resignation effects-of this behavior for targets, sources, and third persons.

\section{Practical Implications}

As phubbing is a real-life phenomenon with real-life consequences, we also want to discuss the practical implications of the present work. While it is concerning that phubbing appears to negatively affect targets, sources, and third persons, this circumstance could entail a positive outcome in that it may inspire interventions to foster more competent social smartphone use. More specifically, observer effects could be disseminated to sensitize smartphone users to the consequences of their own phone-snubbing behaviors without creating defensive responses. Smartphones have become integral parts of people's lives; so much that people get distressed when their smartphones are out of reach (Cheever et al., 2014; Konok et al., 2017) and anxious when notifications or messages are not immediately attended (Clayton et al., 2015). Some smartphone users even state that they cannot imagine life without their mobile device (Gezgin \& Çakır, 2016; Yildirim \& Correia, 2015). Such studies also show that these experiences are not necessarily associated with smartphone addiction but often reported by regular smartphone users. Consequently, it seems difficult to persuade people to reduce their phubbing behavior simply by advising them to do so. On the other hand, putting individuals in the situation of being a target of phubbing in order to demonstrate its negative effects may also be counterproductive as it has been suggested that the 
experience of phubbing may trigger urges to engage in reciprocal phubbing (Chotpitayasunondh \& Douglas, 2016) and turn to social media (David \& Roberts, 2017). Yet, encouraging smartphone users to mindfully examine phubbing in other people's interactions and to become aware of how such behaviors make them feel as observers, may be a simple but effective way to reduce socially disruptive smartphone use. As the present study is, to our knowledge, the first of its kind, future research should further examine the outcomes of observed phubbing to deepen our understanding concerning the phenomenon and to examine whether interventions such as this are feasible.

\section{Limitations}

We want to acknowledge that our study has limitations and urge future research to consider our shortcomings. First, the experiment conducted here merely relied on photo material to portray phubbing. While photos can be great tools to illustrate various types of situations, they lack the ability to show processes leading to the exhibited point in time. In fact, in the context of this study, the question of how individuals initiated the phubbing behavior might have been important for participants since it determines whether smartphone use represents an act of exclusion or not. Without this knowledge, there is a lot of room for subjective interpretations of the situation potentially distorting the effects of phubbing. Furthermore, while our photographers tried to capture the same body postures of the man and the woman across conditions, small variations in facial expressions may have occurred. This possible confounder should be regarded in future research where photo editing software may be utilized to create coherent photo material. Also, in order to cancel out some contextual influences, we chose to collapse the data of repeated measures from three presentations of phubbing in different everyday contexts. However, it might be that the effect of phubbing on observers-particularly the effect on their attitudes concerning the shown individuals-might have been accelerated as they saw the same person phubbing multiple times. This circumstance might have also interfered with the examination of reflexive effects. As explained earlier, reflexive affective effects occur immediately and automatically after the exclusion event. Yet, as participants saw multiple pictures of smartphone-induced social exclusion they might have become increasingly aware of the dismissive nature of phubbing. Consequently, instead of acquiring reflexive affective effects, our study might have detected a combination of reflexive and reflective affective effects. It should be noted, however, that the measurement of reflexive effects through subjective self-report instruments is in general a difficult endeavor as such effects are fleeting. Consequently, if applicable, a combination of subjective and physiological measures should be applied in this context. Finally, participation in this study was quite lengthy and due to its online conduction, we were unable to control for environmental influences or observe potential declines in participants' attention. We therefore advise future research to examine short- and long-term effects of phubbing in experimental settings with high experimental control and high ecological validity. New technologies such as Virtual or Augmented Reality may be harnessed for this endeavor.

\section{Conclusion}

In conclusion, the present study delivers first insights into the adverse effects of phubbing, as an act of smartphone-induced social exclusion, on observers' affective well-being and interpersonal evaluations. Our findings support the assumption that phone-snubbing does not only affect immediate interaction partners but the broader public sphere surrounding social interactions in which the behavior occurs. Therewith, this study emphasizes the necessity for future scientific attention concerning this problematic communication phenomenon and encourages professionals to study and initiate intervention programs for a more competent and healthier social smartphone use.

\section{Acknowledgements}

The authors thank Alina Grewe, Lisa-Marie Trienens, Christopher Kowalczyk, Dano Nitschke, and Ba Tue Freddy Tran for their assistance in conducting this study. This research is co-funded by the MIWF (Ministry for Innovation, Science, and Research NRW) via the Institute of Positive Computing at the University of Applied Sciences Ruhr West. 


\section{References}

Aagaard, J. (2020). Digital akrasia: A qualitative study of phubbing. Al \& Society, 35(1), 237-244.

https://doi.org/10.1007/s00146-019-00876-0

Al-Saggaf, Y., \& MacCulloch, R. (2019). Phubbing and social relationships: Results from an Australian sample. Journal of Relationships Research, 10, Article e10. https://doi.org/10.1017/jrr.2019.9

Al-Saggaf, Y., \& O'Donnell, S. B. (2019). Phubbing: Perceptions, reasons behind, predictors, and impacts. Human Behavior and Emerging Technologies, 1(2), 132-140. https://doi.org/10.1002/hbe2.137

Andone, I., Błaszkiewicz, K., Eibes, M., Trendafilov, B., Montag, C., \& Markowetz, A. (2016). How age and gender affect smartphone usage. In UbiComp '16: Proceedings of the 2016 ACM international Joint Conference on Pervasive and Ubiquitous Computing: Adjunct (pp. 9-12). ACM. https://doi.org/10.1145/2968219.2971451

Baumeister, R. F., \& Leary, M. R. (1995). The need to belong: Desire for interpersonal attachments as a fundamental human motivation. Psychological Bulletin, 117(3), 497-529. https://doi.org/10.1037/00332909.117.3.497

Baumeister, R. F., \& Sommer, K. L. (1997). What do men want? Gender differences and two spheres of belongingness: Comment on Cross and Madson. Psychological Bulletin, 122(1), 38-44.

https://doi.org/10.1037/0033-2909.122.1.38

Benenson, J. F., Markovits, H., Hultgren, B., Nguyen, T., Bullock, G., \& Wrangham, R. (2013). Social exclusion: More important to human females than males. PLoS One, 8(2), Article e55851.

https://doi.org/10.1371/journal.pone.0055851

Benenson, J. F., Markovits, H., Thompson, M. E., \& Wrangham, R. W. (2011). Under threat of social exclusion, females exclude more than males. Psychological Science, 22(4), 538-544.

https://doi.org/10.1177/0956797611402511

Blackhart, G. C., Eckel, L. A., \& Tice, D. M. (2007). Salivary cortisol in response to acute social rejection and acceptance by peers. Biological Psychology, 75(3), 267-276. https://doi.org/10.1016/j.biopsycho.2007.03.005

Bourgeois, K. S., \& Leary, M. R. (2001). Coping with rejection: Derogating those who choose us last. Motivation and Emotion, 25(2), 101-111. https://doi.org/10.1023/A:1010661825137

Buckley, K. E., Winkel, R. E., \& Leary, M. R. (2004). Reactions to acceptance and rejection: Effects of level and sequence of relational evaluation. Journal of Experimental Social Psychology, 40(1), 14-28.

https://doi.org/10.1016/S0022-1031(03)00064-7

Cheever, N. A., Rosen, L. D., Carrier, L. M., \& Chavez, A. (2014). Out of sight is not out of mind: The impact of restricting wireless mobile device use on anxiety levels among low, moderate and high users. Computers in Human Behavior, 37, 290-297. https://doi.org/10.1016/j.chb.2014.05.002

Chotpitayasunondh, V., \& Douglas, K. M. (2016). How "phubbing" becomes the norm: The antecedents and consequences of snubbing via smartphone. Computers in Human Behavior, 63, 9-18.

https://doi.org/10.1016/j.chb.2016.05.018

Chotpitayasunondh, V., \& Douglas, K. M. (2018). The effects of "phubbing" on social interaction. Journal of Applied Social Psychology, 48(6), 304-316. https://doi.org/10.1111/jasp.12506

Clayton, R. B., Leshner, G., \& Almond, A. (2015). The extended iSelf: The impact of iPhone separation on cognition, emotion, and physiology. Journal of Computer-Mediated Communication, 20(2), 119-135.

https://doi.org/10.1111/jcc4.12109 
Coyne, S. M., Nelson, D. A., Robinson, S. L., \& Gundersen, N. C. (2011). Is viewing ostracism on television distressing? The Journal of Social Psychology, 151(3), 213-217. https://doi.org/10.1080/00224540903365570

Cuddy, A. J. C., Fiske, S. T., \& Glick, P. (2008). Warmth and competence as universal dimensions of social perception: The stereotype content model and the BIAS map. In M. P. Zanna (Ed.), Advances in experimental social psychology (Vol. 40, pp. 61-149). Elsevier. https://doi.org/10.1016/S0065-2601(07)00002-0

David, M. E., \& Roberts, J. A. (2017). Phubbed and alone: Phone snubbing, social exclusion, and attachment to social media. Journal of the Association for Consumer Research, 2(2), 155-163. https://doi.org/10.1086/690940

Diener, E., Wirtz, D., Tov, W., Kim-Prieto, C., Choi, D.-W., Oishi, S., \& Biswas-Diener, R. (2010). New well-being measures: Short scales to assess flourishing and positive and negative feelings. Social Indicators Research, 97(2), 143-156. https://doi.org/10.1007/s11205-009-9493-y

Downey, G., Mougios, V., Ayduk, O., London, B. E., \& Shoda, Y. (2004). Rejection sensitivity and the defensive motivational system: Insights from the startle response to rejection cues. Psychological Science, 15(10), 668-673. https://doi.org/10.1111/j.0956-7976.2004.00738.x

Elhai, J. D., Dvorak, R. D., Levine, J. C., \& Hall, B. J. (2017). Problematic smartphone use: A conceptual overview and systematic review of relations with anxiety and depression psychopathology. Journal of Affective Disorders, 207, 251-259. https://doi.org/10.1016/j.jad.2016.08.030

Ergün, N., Göksu, I., \& Sakız, H. (2019). Effects of phubbing: Relationships with psychodemographic variables. Psychological Reports. Advance online publication. https://doi.org/10.1177/0033294119889581

Fletcher, G. J. O., Simpson, J. A., Thomas, G., \& Giles, L. (1999). Ideals in intimate relationships. Journal of Personality and Social Psychology, 76(1), 72-89. https://doi.org/10.1037/0022-3514.76.1.72

Gezgin, D. M., \& Çakır, Ö. (2016). Analysis of nomofobic behaviors of adolescents regarding various factors. Journal of Human Sciences, 13(2), 2504-2519. https://doi.org/10.14687/jhs.v13i2.3797

Giesen, A., \& Echterhoff, G. (2018). Do I really feel your pain? Comparing the effects of observed and personal ostracism. Personality and Social Psychology Bulletin, 44(4), 550-561. https://doi.org/10.1177/0146167217744524

Gonsalkorale, K., \& Williams, K. D. (2007). The KKK won't let me play: Ostracism even by a despised outgroup hurts. European Journal of Social Psychology, 37(6), 1176-1186. https://doi.org/10.1002/ejsp.392

Gonzales, A. L., \& Wu, Y. (2016). Public cellphone use does not activate negative responses in others... Unless they hate cellphones. Journal of Computer-Mediated Communication, 21(5), 384-398.

https://doi.org/10.1111/jcc4.12174

Guazzini, A., Duradoni, M., Capelli, A., \& Meringolo, P. (2019). An explorative model to assess individuals' phubbing risk. Future Internet, 11(1), Article 21. https://doi.org/10.3390/fi11010021

Hales, A. H., Dvir, M., Wesselmann, E. D., Kruger, D. J., \& Finkenauer, C. (2018). Cell phone-induced ostracism threatens fundamental needs. The Journal of Social Psychology, 158(4), 460-473.

https://doi.org/10.1080/00224545.2018.1439877

Hayes, A. F. (2018). Introduction to mediation, moderation, and conditional process analysis second edition: A regression-based approach. The Guilford Press.

Kadylak, T., Makki, T. W., Francis, J., Cotten, S. R., Rikard, R. V., \& Sah, Y. J. (2018). Disrupted copresence: Older adults' views on mobile phone use during face-to-face interactions. Mobile Media \& Communication, 6(3), 331-349. https://doi.org/10.1177/2050157918758129 
Karadağ, E., Tosuntaş, Ş. B., Erzen, E., Duru, P., Bostan, N., Şahin, B. M., Çulha, I., \& Babadağ, B. (2015). Determinants of phubbing, which is the sum of many virtual addictions: A structural equation model. Journal of Behavioral Addictions, 4(2), 60-74. https://doi.org/10.1556/2006.4.2015.005

Kimbrough, A. M., Guadagno, R. E., Muscanell, N. L., \& Dill, J. (2013). Gender differences in mediated communication: Women connect more than do men. Computers in Human Behavior, 29(3), 896-900. https://doi.org/10.1016/j.chb.2012.12.005

Konok, V., Pogány, Á., \& Miklósi, Á. (2017). Mobile attachment: Separation from the mobile phone induces physiological and behavioural stress and attentional bias to separation-related stimuli. Computers in Human Behavior, 71, 228-239. https://doi.org/10.1016/j.chb.2017.02.002

Krasnova, H., Abramova, O., Notter, I., \& Baumann, A. (2016). Why phubbing is toxic for your relationship: Understanding the role of smartphone jealousy among" generation Y" users. In ECIS 2016 Proceedings. https://aisel.aisnet.org/ecis2016_rp/109

Kushlev, K., Dwyer, R., \& Dunn, E. W. (2019). The social price of constant connectivity: Smartphones impose subtle costs on well-being. Current Directions in Psychological Science, 28(4), 347-352.

https://doi.org/10.1177/0963721419847200

Kushlev, K., \& Heintzelman, S. J. (2018). Put the phone down: Testing a complement-interfere model of computer-mediated communication in the context of face-to-face interactions. Social Psychological and Personality Science, 9(6), 702-710. https://doi.org/10.1177/1948550617722199

Leary, M. R., Haupt, A. L., Strausser, K. S., \& Chokel, J. T. (1998). Calibrating the sociometer: The relationship between interpersonal appraisals and the state self-esteem. Journal of Personality and Social Psychology, 74(5), 1290-1299. https://doi.org/10.1037/0022-3514.74.5.1290

Maner, J. K., DeWall, C. N., Baumeister, R. F., \& Schaller, M. (2007). Does social exclusion motivate interpersonal reconnection? Resolving the" porcupine problem.". Journal of Personality and Social Psychology, 92(1), 42-55. https://doi.org/10.1037/0022-3514.92.1.42

Masten, C. L., Eisenberger, N. I., Pfeifer, J. H., Colich, N. L., \& Dapretto, M. (2013). Associations among pubertal development, empathic ability, and neural responses while witnessing peer rejection in adolescence. Child Development, 84(4), 1338-1354. https://doi.org/10.1111/cdev.12056

Masten, C. L., Eisenberger, N. I., Pfeifer, J. H., \& Dapretto, M. (2013). Neural responses to witnessing peer rejection after being socially excluded: fMRI as a window into adolescents' emotional processing. Developmental Science, 16(5), 743-759. https://doi.org/10.1111/desc.12056

Masten, C. L., Morelli, S. A., \& Eisenberger, N. I. (2011). An fMRI investigation of empathy for 'social pain' and subsequent prosocial behavior. Neuroimage, 55(1), 381-388. https://doi.org/10.1016/j.neuroimage.2010.11.060

McDaniel, B. T., \& Coyne, S. M. (2016). Technology interference in the parenting of young children: Implications for mothers' perceptions of coparenting. The Social Science Journal, 53(4), 435-443.

https://doi.org/10.1016/j.soscij.2016.04.010

Mertler, C. A., \& Reinhart, R. V. (2016). Advanced and multivariate statistical methods: Practical application and interpretation (6th ed.). Routledge.

Murray, S. L., Rose, P., Bellavia, G. M., Holmes, J. G., \& Kusche, A. G. (2002). When rejection stings: How selfesteem constrains relationship-enhancement processes. Journal of Personality and Social Psychology, 83(3), 556573. https://doi.org/10.1037/0022-3514.83.3.556 
Muscanell, N. L., \& Guadagno, R. E. (2012). Make new friends or keep the old: Gender and personality differences in social networking use. Computers in Human Behavior, 28(1), 107-112. https://doi.org/10.1016/j.chb.2011.08.016

Nazir, T., \& Pişkin, M. (2016). Phubbing: A technological invasion which connected the world but disconnected humans. The International Journal of Indian Psychology, 3(4), 2348-5396. https://ijip.in/articles/phubbing-atechnological-invasion-which-connected-the-world-but-disconnected-humans/

Park, Y. O., \& Park, S. H. (2015). Observing social exclusion leads to dehumanizing the victim. Frontiers in Psychology, 6, Article 1815. https://doi.org/10.3389/fpsyg.2015.01815

Parmaksiz, I. (2019). Relationship of phubbing, a behavioral problem, with assertiveness and passiveness: A study on adolescents. International Online Journal of Educational Sciences, 11(3), 34-45.

https://doi.org/10.15345/iojes.2019.03.003

Pituch, K. A., \& Stevens, J. P. (2015). Applied multivariate statistics for the social sciences: Analyses with SAS and IBM's SPSS (6th ed.). Routledge.

Preacher, K. J., \& Kelley, K. (2011). Effect size measures for mediation models: Quantitative strategies for communicating indirect effects. Psychological Methods, 16(2), 93-115. https://doi.org/10.1037/a0022658

Przybylski, A. K., \& Weinstein, N. (2013). Can you connect with me now? How the presence of mobile communication technology influences face-to-face conversation quality. Journal of Social and Personal Relationships, 30(3), 237-246. https://doi.org/10.1177/0265407512453827

Richardson, J. T. E. (2011). Eta squared and partial eta squared as measures of effect size in educational research. Educational Research Review, 6(2), 135-147. https://doi.org/10.1016/j.edurev.2010.12.001

Roberts, J. A., \& David, M. E. (2016). My life has become a major distraction from my cell phone: Partner phubbing and relationship satisfaction among romantic partners. Computers in Human Behavior, 54, 134-141. https://doi.org/10.1016/j.chb.2015.07.058

Sbarra, D. A., Briskin, J. L., \& Slatcher, R. B. (2019). Smartphones and close relationships: The case for an evolutionary mismatch. Perspectives on Psychological Science, 14(4), 596-618.

https://doi.org/10.1177/1745691619826535

Stroud, L. R., Salovey, P., \& Epel, E. S. (2002). Sex differences in stress responses: Social rejection versus achievement stress. Biological Psychiatry, 52(4), 318-327. https://doi.org/10.1016/S0006-3223(02)01333-1

Turkle, S. (2011). Alone together: Why we expect more from technology and less from each other. Basic Books.

Twenge, J. M., \& Martin, G. N. (2020). Gender differences in associations between digital media use and psychological well-being: Evidence from three large datasets. Journal of Adolescence, 79, 91-102.

https://doi.org/10.1016/j.adolescence.2019.12.018

Umari, T., Rusandi, M. A., \& Yakub, E. (2019). Phubbing as a result of the 4th Industrial Revolution: Is it dangerous? In N. Islami \& R. linda (Eds.), Proceedings of the SS9 and 3rd URICES (pp.230-236).

https://ices.prosiding.unri.ac.id/index.php/ICES/article/view/7896

van Deursen, A. J. A. M., Bolle, C. L., Hegner, S. M., \& Kommers, P. A. M. (2015). Modeling habitual and addictive smartphone behavior: The role of smartphone usage types, emotional intelligence, social stress, self-regulation, age, and gender. Computers in Human Behavior, 45, 411-420. https://doi.org/10.1016/j.chb.2014.12.039

Vanden Abeele, M. M. P. (2020). The social consequences of phubbing: A framework and a research agenda. In R. Ling, L. Fortunati, G. Goggin, S. S. Lim, \& Y. Li (Eds.), The Oxford handbook of mobile communication and society (pp. 158-174). Oxford University Press. 
Vanden Abeele, M. M. P., Antheunis, M. L., \& Schouten, A. P. (2016). The effect of mobile messaging during a conversation on impression formation and interaction quality. Computers in Human Behavior, 62, 562-569. https://doi.org/10.1016/j.chb.2016.04.005

Vanden Abeele, M. M. P., Hendrickson, A. T., Pollmann, M. M. H., \& Ling, R. (2019). Phubbing behavior in conversations and its relation to perceived conversation intimacy and distraction: An exploratory observation study. Computers in Human Behavior, 100, 35-47. https://doi.org/10.1016/j.chb.2019.06.004

Verma, J. P. (2015). Repeated measures design for empirical researchers. John Wiley \& Sons.

Wang, X., Xie, X., Wang, Y., Wang, P., \& Lei, L. (2017). Partner phubbing and depression among married Chinese adults: The roles of relationship satisfaction and relationship length. Personality and Individual Differences, 110, 12-17. https://doi.org/10.1016/j.paid.2017.01.014

Warner, R. M. (2012). Applied statistics: From bivariate through multivariate techniques (2nd ed.). Sage Publications.

Wesselmann, E. D., Bagg, D., \& Williams, K. D. (2009). "I feel your pain": The effects of observing ostracism on the ostracism detection system. Journal of Experimental Social Psychology, 45(6), 1308-1311.

https://doi.org/10.1016/j.jesp.2009.08.003

Williams, K. D. (2007). Ostracism. Annual Review of Psychology, 58, 425-452.

https://doi.org/10.1146/annurev.psych.58.110405.085641

Williams, K. D. (2009). Ostracism: A temporal need-threat model. In M. P. Zanna (Ed.), Advances in experimental social psychology (Vol. 41, pp. 275-314). Elsevier. https://doi.org/10.1016/S0065-2601(08)00406-1

Williams, K. D., Cheung, C. K. T., \& Choi, W. (2000). Cyberostracism: Effects of being ignored over the Internet. Journal of Personality and Social Psychology, 79(5), 748-762. https://doi.org/10.1037/0022-3514.79.5.748

Wolniewicz, C. A., Tiamiyu, M. F., Weeks, J. W., \& Elhai, J. D. (2018). Problematic smartphone use and relations with negative affect, fear of missing out, and fear of negative and positive evaluation. Psychiatry Research, 262, 618-623. https://doi.org/10.1016/j.psychres.2017.09.058

Yildirim, C., \& Correia, A.-P. (2015). Exploring the dimensions of nomophobia: Development and validation of a self-reported questionnaire. Computers in Human Behavior, 49, 130-137.

https://doi.org/10.1016/j.chb.2015.02.059

Zadro, L., Boland, C., \& Richardson, R. (2006). How long does it last? The persistence of the effects of ostracism in the socially anxious. Journal of Experimental Social Psychology, 42(5), 692-697.

https://doi.org/10.1016/j.jesp.2005.10.007

Zadro, L., Williams, K. D., \& Richardson, R. (2004). How low can you go? Ostracism by a computer is sufficient to lower self-reported levels of belonging, control, self-esteem, and meaningful existence. Journal of Experimental Social Psychology, 40(4), 560-567. https://doi.org/10.1016/j.jesp.2003.11.006 


\section{Appendix}

Table A1. Utilized Items for the Measurement of Positive and Negative Affect.

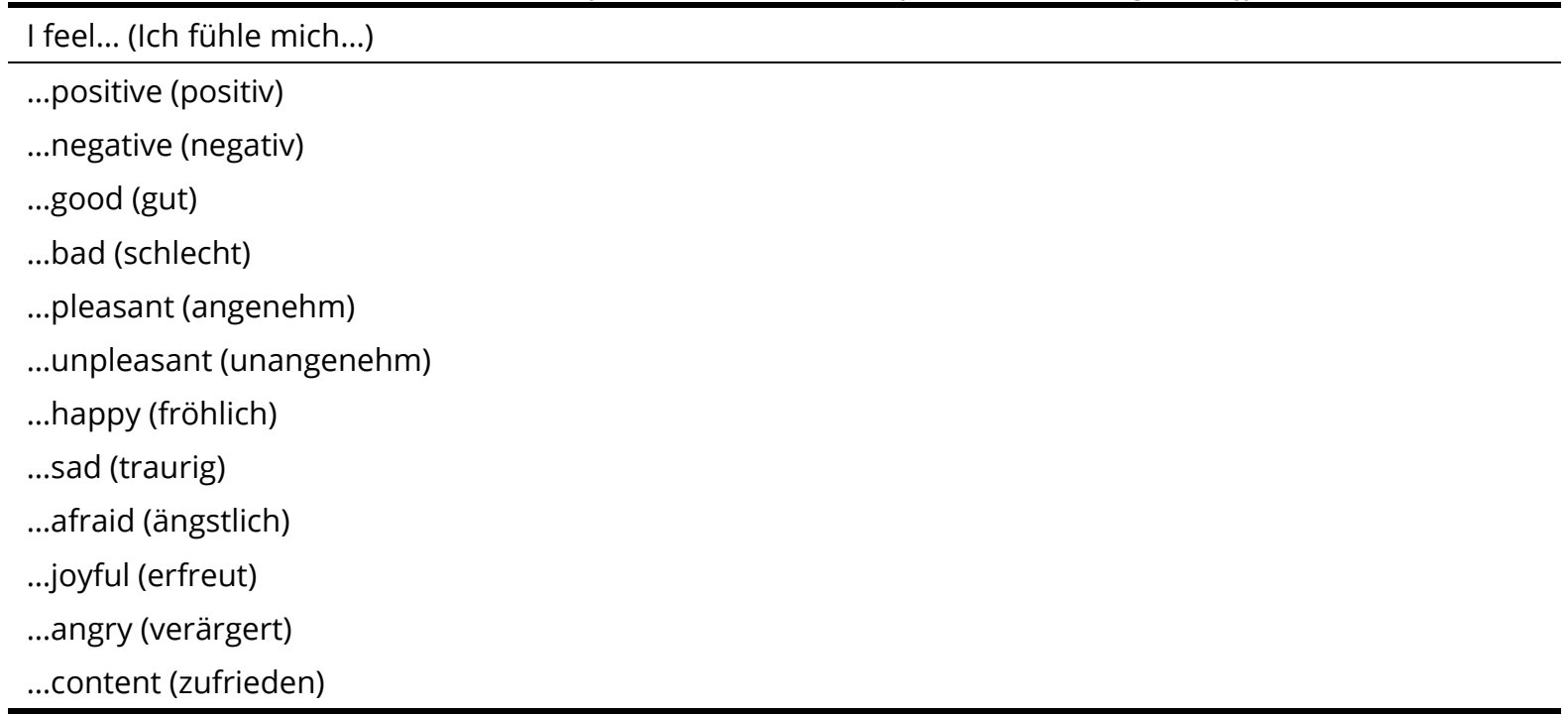

Note. Items were derived from the Scale of Positive and Negative Experience (SPANE; Diener et al., 2010) and translated into German. The German items are presented in parentheses alongside the original items.

Table A2. Utilized Items for the Measurement of Perceived Relationship Quality.

The two people... (Beide Personen....)

...know each other well (kennen sich gut)

....are very familiar with each other (sind sehr vertraut)

...harmonize with each other (harmonieren gut miteinander)

...get along well (verstehen sich gut)

...communicate well with each other (kommunizieren gut)

...are friends (sind gut befreundet)

...trust each other (vertrauen einander)

....are in love (sind verliebt)

...are closely connected (sind eng verbunden)

...are honest with each other (sind ehrlich zueinander)

Note. Items were developed based on the Partner and Relationship Ideal Scales (Fletcher et al., 1999). The German items utilized in this study are presented in parentheses.

Table A3. Utilized Items for the Measurement of Person Evaluation Concerning Warmth and Competence.

The person is... (Die Person ist...)

...competent (kompetent)

...self-confident (selbstsicher) ${ }^{1}$

...efficient (leistungsfähig) 1

...intelligent (intelligent) ${ }^{1}$

...skillful (qualifiziert) ${ }^{1}$

...friendly (freundlich) ${ }^{2}$

...trustworthy (vertrauenswürdig)²

...reliable (zuverlässig)²

...warm (warm)2

...sincere (ehrlich) ${ }^{2}$

...good-natured (gutmütig) ${ }^{2}$

Note. Items were derived from the Stereotype Content Model (SCM; Cuddy, et al., 2008) and translated into German.

The German items are presented in parentheses alongside the original items.

${ }^{1}$ Subscale Competence

${ }^{2}$ Subscale Warmth 


\section{Correspondence to:}

Tania R. Nuñez

Institute of Psychology, University of Wuppertal

Gaußstr. 20

42119 Wuppertal

Germany

Email: tania.nunez(at)uni-wuppertal.de

Editorial record: First submission received on November 3, 2019. Revisions received on May 7, 2020 and July 2, 2020. Accepted for publication on July 2, 2020.

Editor in charge: Alexander Schouten

\section{About Authors}

Tania Roxana Nuñez, M.A. (tania.nunez(at)uni-wuppertal.de) is a Ph.D. student at the Institute of Psychology at the University of Wuppertal, Germany and a researcher in the School of Psychology and Psychotherapy at the Witten/Herdecke University, Germany. Her research focuses on problematic technology use. She is particularly interested in the adverse effects of co-present smartphone use (i.e., phubbing) on individual well-being and social relationships.

Theda Radtke, Ph.D. (theda.radtke(at)uni-wh.de) is a professor of Health, Work, and Organizational Psychology at the Department of Psychology of the Witten/Herdecke University, Germany. Her research focuses on health behavior change (e.g., timeouts from smartphone use) as well as on risk factors underlying health behaviors (e.g., compensatory health beliefs). In this context, the investigation of individual self-regulation is just as important as the exploration of social exchange processes.

Sabrina C. Eimler, Ph.D. (sabrina.eimler(at)hs-ruhrwest.de) is a professor for Human Factors \& Gender Studies at the Institutes of Computer Science and Positive Computing at the University of Applied Sciences Ruhr West in Bottrop. Her recent research focuses on social Al; e.g. Human-Al-Collaboration and the development of an Albased social companion that helps teenagers deal with toxic content in social media. 